\title{
Purification of Free Lutein from Marigold Flowers by Liquid Chromatography
}

\author{
Panatpong Boonnoun ${ }^{1}$, Thanawich Opaskonkun ${ }^{1}$, Phattanon Prasitchoke ${ }^{2}$, \\ Motonobu Goto ${ }^{3}$, and Artiwan Shotipruk ${ }^{1, *}$
}

1 Chemical Engineering Research Unit for Value Adding of Bioresources, Department of Chemical Engineering, Faculty of Engineering, Chulalongkorn University, Phayathai Road, Patumwan, Bangkok 10330, Thailand

2 PTT Global Chemical Public Company Limited, Amphur Mueang Rayong, Rayong 21150, Thailand 3 Graduate School of engineering, Nagoya University, Furo-cho, Chikusa-ku, Nagoya, 464-8603, Japan

*E-mail: artiwan.sh@chula.ac.th

\begin{abstract}
Marigold is a rich source of a Xanthophyll called lutein, which shows antioxidant and anti-cancer activities and is beneficial to eye health. This has led to various extraction and purification studies to obtain the high purity free lutein suitable for human applications. Liquid chromatography is extensively used to purify high value natural compounds because the process results in high purity products. The suitable mobile phase and stationary phase are the key factors to achieve high purity. In this work, chromatographic separation of lutein extracted from marigold flowers was investigated, using silica gel and mixture of hexane:ethyl acetate as a stationary and a mobile phase, respectively. Initially, the suitable composition of hexane:ethyl acetate was determined using a thin layer chromatography. Hexane:ethyl acetate mixture at 70:30 volume ratio was found to be an appropriate mobile phase for a normal phase chromatographic separation of free lutein. Preliminary experiments on a semi-preparative and a preparative column carried out at the mobile phase flow rate of $10 \mathrm{ml} / \mathrm{min}$ suggested that as high as $97.1 \%$ purity free lutien could be obtained with a $60 \%$ approximate yield. Moreover, since the separation by chromatography arises from the adsorption of free lutein onto silica gel, thus to better understand the process, a batch adsorption study was carried out to obtain the equilibrium adsorption data. The isotherm plotted from these data was found to be reasonably described by Langmuir adsorption model.
\end{abstract}

Keywords: Preparative chromatographic purification, free lutein, marigold flower, adsorption isotherm.

ENGINEERING JOURNAL Volume 16 Issue 5

Received 20 February 2012

Accepted 6 June 2012

Published 1 October 2012

Online at http://www.engj.org/

DOI:10.4186/ej.2012.16.5.145 


\section{Introduction}

Marigold flower is one of the richest sources of natural carotenoids. The major carotenoid in marigold is lutein, which has been reported to be beneficial in several aspects to human health such as supporting eyes and skin, and reducing the failure of the eyesight due to age-related macular degeneration (AMD), coronary heart disease and cancer [1]. Therefore, lutein has gained much interest due to its potential in nutraceutical and pharmaceutical applications.

In marigold flowers, lutein generally exists in the form of lutein fatty acid esters. Conventional method for marigold lutein fatty acid esters extraction is achieved by solvent extraction (generally using hexane). Alternatively, the environment friendly and non-toxic extraction solvent such as supercritical carbon dioxide $\left(\mathrm{SC}-\mathrm{CO}_{2}\right)$ can also be used so as to provide milder extraction conditions [2]. Since only in its free form that lutein can be taken up by human body [3-4], marigold extract or marigold oleoresin must therefore be saponified with an alkali solution, i.e. $\mathrm{KOH}$ solution, to obtain free lutein [5]. Unfortunately, the saponified lutein mixture contains many impurities such as soap, oil, unreacted lutein fatty acid esters. Thus, a purification process is generally required to obtain purified lutein for human applications. Crystallization is a common process for purifying free lutein, however it results in rather low yield and purity. Although high purity could be achieved by re-crystallization, the process requires several steps, making it rather complicated, and thus lowering the overall yield [6].

Alternatively, liquid chromatography is extensively used to purify high value compounds from natural product. The development of an appropriate protocol (i.e., the optimization of mobile phase system) for chromatographic purification of a specific compound is generally performed via trial-and-error on an analytical High Performance Liquid Chromatography (HPLC). The isolation procedure on such analytical scales has been reported in existing literatures for free lutein derived from different raw materials, including fruits, vegetables and marigold flowers [7-8]. However, very few reports on chromatographic purification of lutein in larger semi-preparative and preparative scale were found.

In this work, normal phase chromatography with silica gel as a stationary phase was used for purifying free lutein from the saponified marigold oleoresin. Firstly, the suitable mobile phase system was investigated by using a thin layer chromatography (TLC), and with this suitable mobile phase, a preliminary study on an open column semi-preparative chromatography for lutein purification was conducted. Finally, a chromatographic separation was carried out on a preparative column to obtain the high purity free lutein. In addition, since the chromatographic separation arises from the partitioning of lutein between the mobile phase and the stationary phase by adsorption, the study on the adsorption equilibrium will provide better understanding of this process. Batch adsorption experiments were thus carried out to determine the adsorption isotherm of lutein on silica gel. The experimental results were fitted with the linearized forms of various adsorption models, and an appropriate model was proposed.

\section{Materials and Methods}

\subsection{Materials and Chemicals}

Dried marigold flowers were obtained from PTT Grobal Chemical Public Company limited (Rayong, Thailand). All the samples were finely powdered prior to use. Hexane (purity $>99.5 \%$ ) used for solvent extraction, recovery of total xanthophylls and mobile phase of semi-preparative, preparative liquid chromatography was supplied by Sigma-Aldrich. Chemicals used for saponification such as ethanol, potassium hydroxide and hydrochloric acid were purchased from Merck, USA. Diethyl ether was supplied by Merck, Thailand. Silica gel supplied by Merck, Thailand, was used as a chromatography column packing material. Ethyl acetate supplied by Merck, Thailand, was used as one of the components in the mobile phase of semi-preparative and preparative liquid chromatography. Lutein standards (analytical grade) were purchased from Sigma-Aldrich, Germany.

\subsection{Solvent Extraction}

The amount 100 grams of dried marigold powder was extracted with $500 \mathrm{ml}$ of hexane in a $1 \mathrm{~L}$ beaker. The extraction was carried out for $4 \mathrm{~h}$ in a water bath whose temperature was controlled at $40^{\circ} \mathrm{C}$. After extraction, the mixture was left to stand for $20 \mathrm{~min}$ at room temperature to allow the residue to settle. The supernatant was isolated and the caroteniods containing hexane solution was concentrated by a rotary 
evaporator at $40{ }^{\circ} \mathrm{C}$. The extract was then dried by a vacuum oven at $30{ }^{\circ} \mathrm{C}$ for $8 \mathrm{~h}$. The remaining solid (marigold oleoresin) was collected and stored in a refrigerator at $-20^{\circ} \mathrm{C}$ for use in the next saponification step [6].

\subsection{Saponification}

The amount 0.6 of gram $\mathrm{KOH}$ was dissolved in $10 \mathrm{ml}$ of ethanol in a $125 \mathrm{ml}$ flask, into which one gram of marigold oleoresin was then added. The flask was shaken at $150 \mathrm{rpm}$ and $50^{\circ} \mathrm{C}$ for $4 \mathrm{~h}$. After the reaction was completed, $50 \mathrm{ml}$ of ethanol was added into the saponified mixture, and this mixture was then transferred to a separation funnel, into which $100 \mathrm{ml}$ of $5 \% \mathrm{Na}_{2} \mathrm{SO}_{4}$ solution (in distilled water) and $80 \mathrm{ml}$ of diethyl ether were added. All components were allowed to mix, and then separated into two phases. The upper phase (ether fraction) was collected as free lutein stock solution, while the lower phase was discarded water-soluble impurities still remained in the free lutein stock solution were extracted repeatedly with water until the water phase became colorless [9]. The resulting free lutein stock solution was then stored in a $20^{\circ} \mathrm{C}$ refrigerator for use in a column chromatography.

\subsection{Purification by Chromatography}

\subsubsection{Thin layer chromatography experiment}

Silica gel coated thin layer chromatography plates (TLC silica gel 60, 25 Aluminium sheets $20 \times 20 \mathrm{~cm}$, Merck, USA) were used for screening for a proper mobile phase. Lutein stock solution was spotted onto TLC plates, each of which was then placed in a chamber containing the mobile phase of different composition. Mobile phases tested were mixtures at various compositions of hexane and ethyl acetate (at the ratios of 100:0, 90:10, 80:20, 70:30 and 60:40 hexane:ethyl acetate).

\subsubsection{Column packing procedures}

Silica gel was suspended in hexane to the slurry at a concentration of $5 \%(\mathrm{w} / \mathrm{v})$. The suspension was then degassed overnight using a sonicator. The slurry was packed into a $8 \mathrm{~mm} \times 240 \mathrm{~mm}$ semi-preparative open column or a $35 \mathrm{~mm} \times 240 \mathrm{~mm}$ preparative chromatography column.

\subsubsection{Semi-preparative open column chromatography}

The amount 5 grams of silica gel slurry prepared as described above were packed into a glass column $(8 \times 240 \mathrm{~mm})$ and $0.5 \mathrm{ml}$ of lutein stock solution was then loaded into the semi-preparative glass column. Then mobile phase mixture of hexane: ethyl acetate $(70: 30 \mathrm{v} / \mathrm{v})$ was allowed to flow by means of gravity. Fractions were collected on a one minute intervals for the HPLC analysis of free lutein content.

\subsubsection{Preparative column chromatography}

The amount 100 grams of silica gel slurry was packed into a glass column $(35 \times 240 \mathrm{~mm}) .10 \mathrm{ml}$ of lutein stock solution was loaded to the column and eluted with the mixture of hexane: ethyl acetate $(70: 30 \mathrm{v} / \mathrm{v})$. The sample was eluted from the bottom of the column by means of a peristaltic pump (Masterflex, model number 7523-60, Cole Parmer Thailand) at a flow rate of $10 \mathrm{ml} / \mathrm{min}$. The fractions were collected at 10 minute intervals and were analyzed by HPLC.

\subsection{Adsorption of Lutein on Silica Gel}

A known concentration of free lutein stock solution was diluted to give a series of solutions of free lutein whose concentrations range from 2.0 to $12.0 \mu \mathrm{g} \mathrm{ml}^{-1}$. Batch mode adsorption studies were carried out in a $125 \mathrm{ml}$ covered conical flasks by first equilibrating an accurately weighed amount of silica gel (about $1 \mathrm{~g}$ ) with $10 \mathrm{ml}$ of sample solutions of known initial concentration of free lutein. The samples were agitated in an orbital shaker at $120 \mathrm{rpm}$ and $30^{\circ} \mathrm{C}$ for $30 \mathrm{~min}$. After reach equilibrium, the contents of the flask were analyzed for the concentration of free lutein by a spectrophotometer. The concentration of the adsorbed free lutein was calculated by the difference of the known total amount of free lutein and the amount 
measured in the solution after equilibrium. The amount of adsorbed solute $\left(\mathrm{C}_{\mathrm{ad}}, \mu \mathrm{g}\right.$ free lutein $/ \mathrm{g}$ dry silica) was calculated from Eq. (1).

$$
C_{a d}=\frac{\left(V_{0} C_{0}-C_{q e}\left(V_{0}+\Delta V\right)\right)}{W_{d}}
$$

where the dilution volume, $\Delta V(\mathrm{ml})=\left(W_{w}-W_{d}\right) / \rho$ in $\mathrm{ml}, W_{w}$ and $W_{d}$ are the weights of wet and dry silica in $\mathrm{g}$, respectively, $V_{0}$ is the volume of the solution $(\mathrm{ml}), C_{0}$ and $C_{e q}$ are the initial and equilibrium concentrations $(\mu \mathrm{g} / \mathrm{ml})$.

\subsection{Analysis of Free Lutein by High Pressure Liquid Chromatography (HPLC)}

The extracted, saponified and chromatography purified samples were analyzed by HPLC to identify luteins components in the samples. The reversed phase HPLC analysis was carried out using Agilant 1100, Lichrocart C-18 column (30 cm length), a Diode Array Detector Module 335 and an automatic injector. The mobile phase was a gradient solvent system composed of acetonitrile:methanol (9:1,v:v) (A) and ethyl acetate (B). The gradient system was run by linearly increasing solvent B from $0 \%$ to $100 \%$ over $30 \mathrm{~min}$, at a flow rate of $1 \mathrm{ml} / \mathrm{min}$. The sample injection volume was $20 \mu \mathrm{l}$ and the detection wavelength was set at $450 \mathrm{~nm}[10]$.

\subsection{Analysis of Saponified Sample by Liquid Chromatography Mass Spectrometery (LC-MS)}

The saponified sample was analyzed by by HPLC to identify the luteins components. The reversed phase HPLC analysis was carried out using Agilant 1100, Lichrocart C-18 column (15 cm length), a Diode Array Detector Module 335 and an automatic injector. The mobile phase was a gradient solvent system of acetonitrile:methanol $(9: 1, \mathrm{v}: \mathrm{v})$ (A) and ethyl acetate (B), from $0 \%$ to $100 \%$ of $\mathrm{B}$ using a linear gradient injected over $30 \mathrm{~min}$, at a flow rate of $1 \mathrm{ml} / \mathrm{min}$. The eluents were analyzed by Bruker Daltanic Model: Esquire 3000 to confirm mass of free lutein. MS was carried out in the positive ion measurement mode with a detection voltage of $1.6 \mathrm{kV}$, an APCI temperature of $400{ }^{\circ} \mathrm{C}$, a curved desolvation line of $250{ }^{\circ} \mathrm{C}$, and a block temperature of $200{ }^{\circ} \mathrm{C}$. The flow rate of the nebulizer gas was $2.5 \mathrm{ml} / \mathrm{min}$. Full scan spectra were obtained by scanning masses between $\mathrm{m} / \mathrm{z} 200$ and 800 [11].

\subsection{Analysis of Purified Sample by Hydrogen Nuclear Magnetic Resonance Spectrometry (H- NMR)}

Hydrogen Nuclear Magnetic Resonance Spectrometer (H-NMR) was acquired on a Varian INOVA model. All spectra were measured in $\mathrm{CDC1}_{3}$ at $25^{\circ} \mathrm{C}$ with $\mathrm{CP} / \mathrm{MAS}$ solid probe and Nano probe.

\subsection{Analysis of Adsorption Isotherm}

Adsorption data obtained from the experiment were fitted to the Langmuir and Freundlich models (shown in Table 1), to determine which of the models appropriately describes the results.

Table 1. Isotherm models.

\begin{tabular}{lcc}
\hline Name & Equation & Linear form \\
\hline Freundlich model & $C_{a d}=K_{F} C_{e q}^{1 / n}$ & $\log C_{a d}=\log K_{F}+\frac{1}{n} \log C_{e q}$ \\
Langmuir model & $C_{a d}=\frac{K_{L} a_{L} C_{e q}}{1+a_{L} C_{e q}}$ & $\frac{1}{C_{a d}}=\frac{1}{K_{L} a_{L} C_{e q}}+\frac{1}{K_{L}}$ \\
\hline
\end{tabular}




\section{Results and Discussion}

\subsection{Liquid Chromatography Purification}

HPLC and LC-MS analyses were used to determine the components of the saponified samples. The HPLC analysis results indicated that the solution consisted of two major compounds whose retention times were about 10 and $11 \mathrm{~min}$, respectively (Fig. 1). The other impurities in saponified sample were detected at retention times of about 8 and 16 min. The identification of the compounds was then carried out by Liquid chromatography mass spectrometry (LC-MS), which indicated that the two compounds corresponding to the mass of 568 and 551 were, respectively, free lutein and the anhydrolutein, a lutein compound whose molecule was absent of an $\mathrm{OH}$ group (Fig. 2). This anhydrolutein might be a result of oxidization in the presence of oxygen by light or at moderate temperatures [12] during the extraction and saponification processes. LC-MS result of purified sample was compared to LC-MS result of lutein standard from Molnar's work [13]. From LC-MS results, purified sample contains free lutein, anhydrolutein and small amount of other impurities but lutein standard contains only free lutein and anhydrolutein.

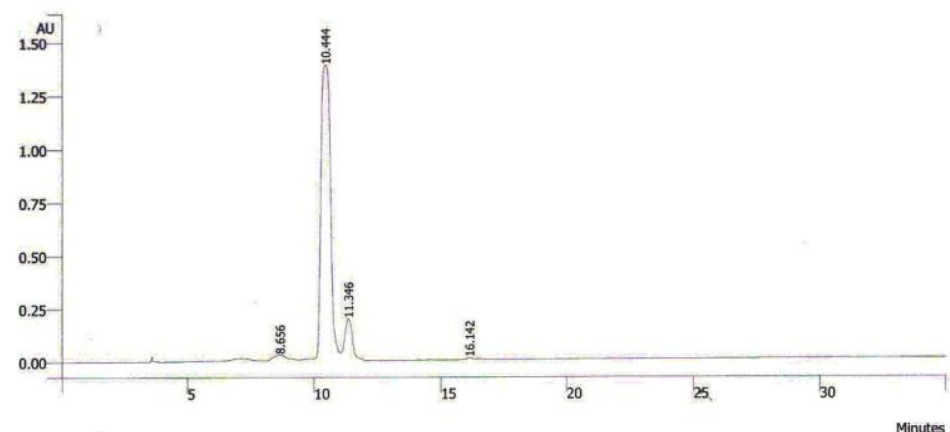

Fig. 1. HPLC chromatogram of saponified lutein sample.

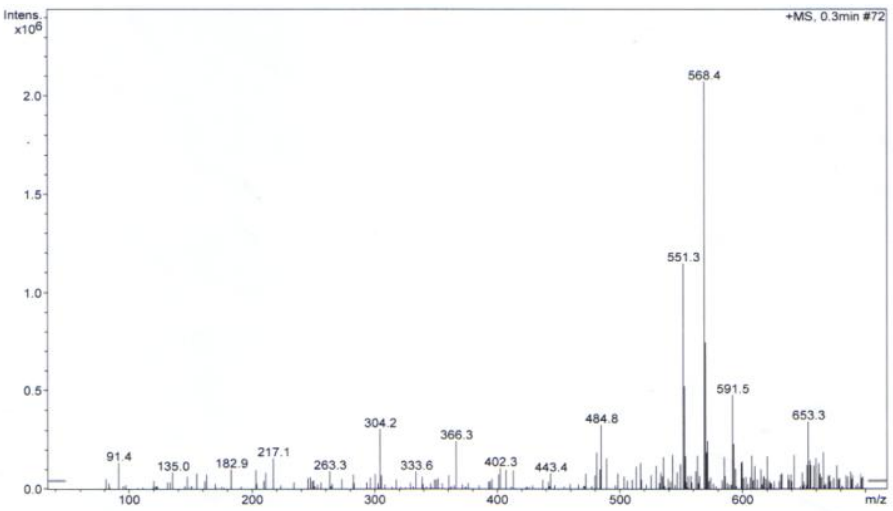

Fig. 2. LC-MS chromatogram of saponified lutein sample.

3.1.1. Screening of mobile phase by thin layer chromatography (TLC)

The hexane:ethyl acetate mixtures of various compositions were tested. The results shown in Fig. 3 indicated that the green spots of the samples were moved upwards from the base line when the mobile phase contains higher volume ratio of ethyl acetate. The most suitable ratio of the mobile phase was found to be 70:30 (hexane: ethyl acetate v/v), giving the clearest separation of the two major components. 


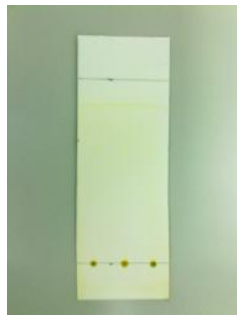

(a)

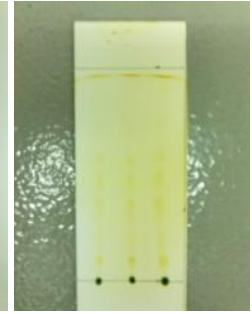

(b)

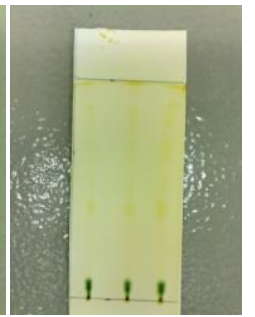

(c)

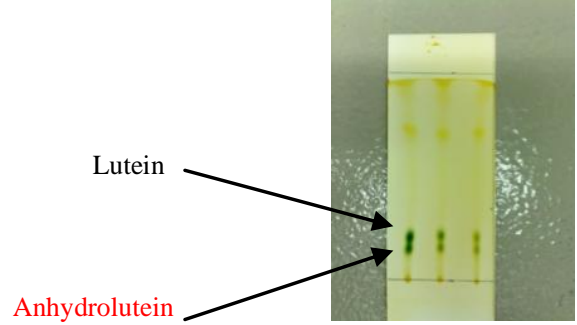

(d)

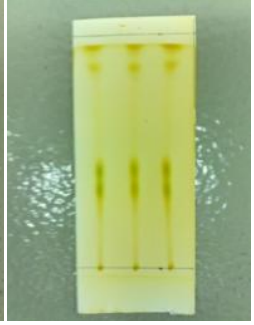

(e)

Fig. 3. Separations on TLC by hexane: ethyl acetate mobile phases at various compositions: (a) hexane: ethyl acetate $=100: 0 \mathrm{v} / \mathrm{v}$, (b) hexane: ethyl acetate $=90: 10 \mathrm{v} / \mathrm{v}$, (c) hexane: ethyl acetate $=80: 20$ $\mathrm{v} / \mathrm{v}$, (d) hexane: ethyl acetate $=70: 30 \mathrm{v} / \mathrm{v}$, (e) hexane: ethyl acetate $=60: 40 \mathrm{v} / \mathrm{v}$.

\subsubsection{Chromatographic purification on semi-preparative and preparative columns}

From the previous experiment, a mixture of hexane and ethyl acetate $(70: 30 \mathrm{v} / \mathrm{v})$ shows the possibility to purify the free lutein from saponified solution. In this section, the $8 \mathrm{~mm} \times 240 \mathrm{~mm}$ open column packed with silica and mixture of hexane and ethyl acetate $(70: 30 \mathrm{v} / \mathrm{v})$ were used for preliminary study of free lutein purification. At this preliminary state, all the collected fractions were combined based on the color of the fractions that was observed visually on the semi-preparative columns as the samples were eluted, where two main color bands were observed: the yellow and the orange bands. The orange fractions eluted from the semi-preparative sample made up to relatively large amounts, which were expected to be mostly free lutein and its decomposed form mentioned above. Therefore the eluted fractions collected from this band were divided into 3 fractions and were analyzed by HPLC, the first and second combined fractions that were eluted from the semi-preparative column contain free lutein at rather high purity, whereas the last combined fractions of the same orange band contained the decomposed form of lutein, and thus has lower free lutein purity.

From the feasibility of semi-preparative column to purify free lutein, the larger scale of preparative chromatography of free lutein was studied for purifying free lutein from the saponified product. Originally, the scale up factor was calculated from the diameter of semi-preparative and preparative chromatography columns as 19.14 (Eq. (2)) which was then used to estimate the operational conditions such as mass of packing material, mobile phase flow rate and sample loading volume. For example, the scale up factor was multiplied by the previous conditions on semi-preparative open column (10 gram of packing material, 2.5 $\mathrm{ml} / \mathrm{min}$ of flow rate and $0.5 \mathrm{ml}$ sample loading). Consequently, the conditions estimated from this factor for the preparative chromatography column were 100 gram of packing material (silica gel), 70:30 v/v of hexane: ethyl acetate mixture mobile phase, the flow rate was at at $50 \mathrm{ml} / \mathrm{min}$ and sample loading was 10 $\mathrm{ml}$. However, due to the limit in the flow rate of the peristaltic pump currently employed in the study, the lower flow rate of $10 \mathrm{ml} / \mathrm{min}$ was used.

$$
\text { Scale up factor }=\frac{\left(\frac{D_{2}}{2}\right)^{2}}{\left(\frac{D_{1}}{2}\right)^{2}}
$$

Similar to semi-preparative purification, the two main color bands of yellow and the orange bands were observed. The purity, yield and amount of free lutein in each fractionated solutions is shown in Table 2 . The first yellow bands were observed at fraction 2, 3 and 4 and the HPLC results show these fractions contain more impurities which were weakly adsorbed on silica gel, thus were eluted easily from the column (but eluted later from the HPLC reversed phase column) (Fig. 4(a)). The colorless fractions were observed at fraction 5, 6 and 7 and no compound could be detected by HPLC from these fractions. The orange 
bands were observed in fraction 8 and 9 and the HPLC results show the higher purity of free lutein at 97.1\% (based on the HPLC peak area ratios) (Fig. 4(b)). Moreover, yield of free lutein which calculated base on the amount of free lutein in stock solution before chromatographic purification was about $61 \%$. The mixed solution of free lutein and anhydrolutein was observed at fraction 10 to 17 (Fig. 4(c)). The purity and yield of free lutein in these fractions were about $65 \%$ and $27 \%$ respectively. After the chromatographic separation, the column was then washed by $100 \%$ ethyl acetate. This washed solution was also analyzed and was found to contain the impurities which were most strongly adsorbed on silica and also a small amount of free lutein (Fig. 4(d)).

Table 2. Purity, yield and amount of free lutein in each fractionation solutions.

\begin{tabular}{lcccc}
\hline Fraction number & Fraction color & $\begin{array}{c}\text { Amount of free } \\
\text { lutein } \\
\text { detected by } \\
\text { HPLC (mg) }\end{array}$ & $\begin{array}{c}\text { \% Yield of free } \\
\text { lutein (\%) }\end{array}$ & $\begin{array}{c}\text { Purity of free } \\
\text { lutein (\%) }\end{array}$ \\
\hline 1 & Colorless & Not detected & 0 & 0 \\
$2-4$ & Yellow & Not detected & 0 & 0 \\
$5-7$ & Colorless & Not detected & 0 & 0 \\
$8-9$ & Orange & $6.43 \pm 0.38$ & $61.78 \pm 3.63$ & $97.1 \pm 1.85$ \\
$10-17$ & Yellow & $2.68 \pm 0.38$ & $25.72 \pm 3.63$ & $66.25 \pm 2.75$ \\
Washed solution & Light yellow & $1.3 \pm 0.02$ & $12.7 \pm 0.02$ & $5 \pm 0.04$ \\
\hline
\end{tabular}

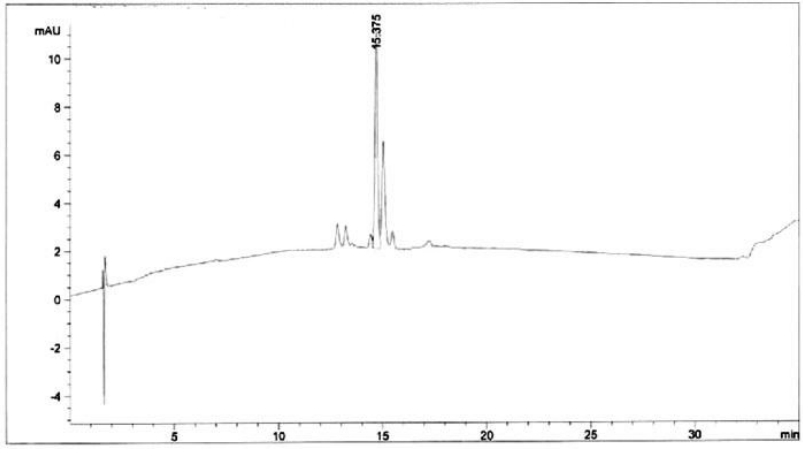

(a)

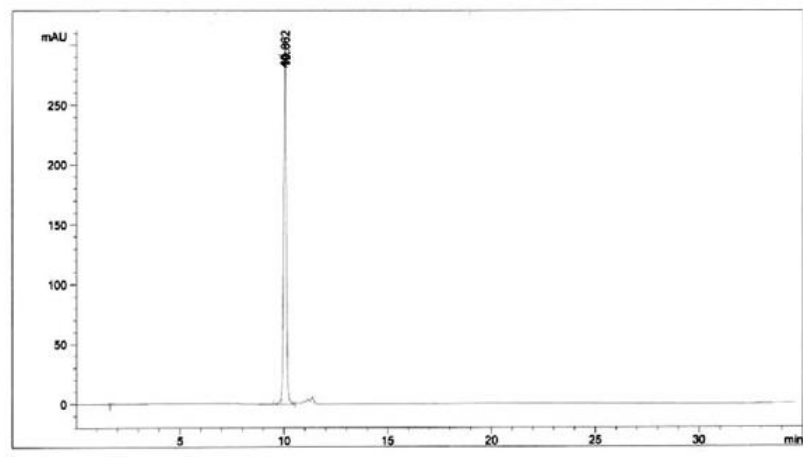

(b) 


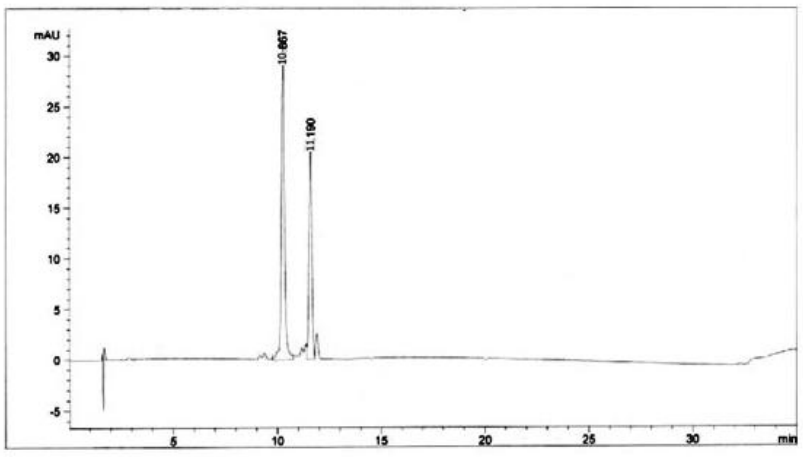

(c)

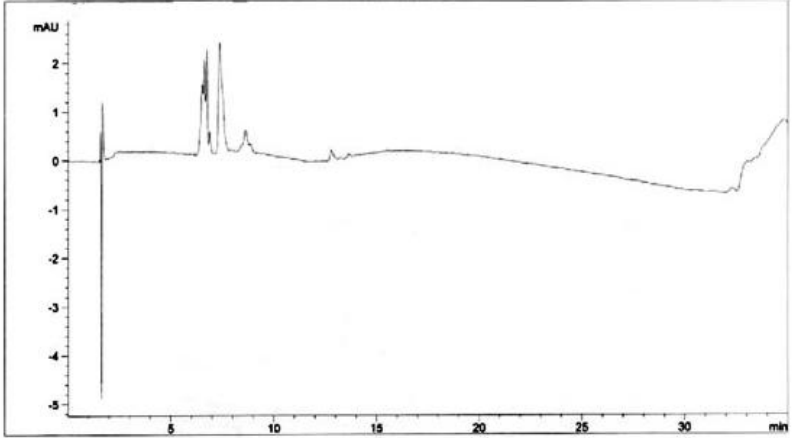

(d)

Fig. 4. HPLC chromatograms of lutein sample after liquid chromatography purification; (a) fraction 2-4, (b) fraction 8-9, (c) fraction 10-17, and (d) washed solution.
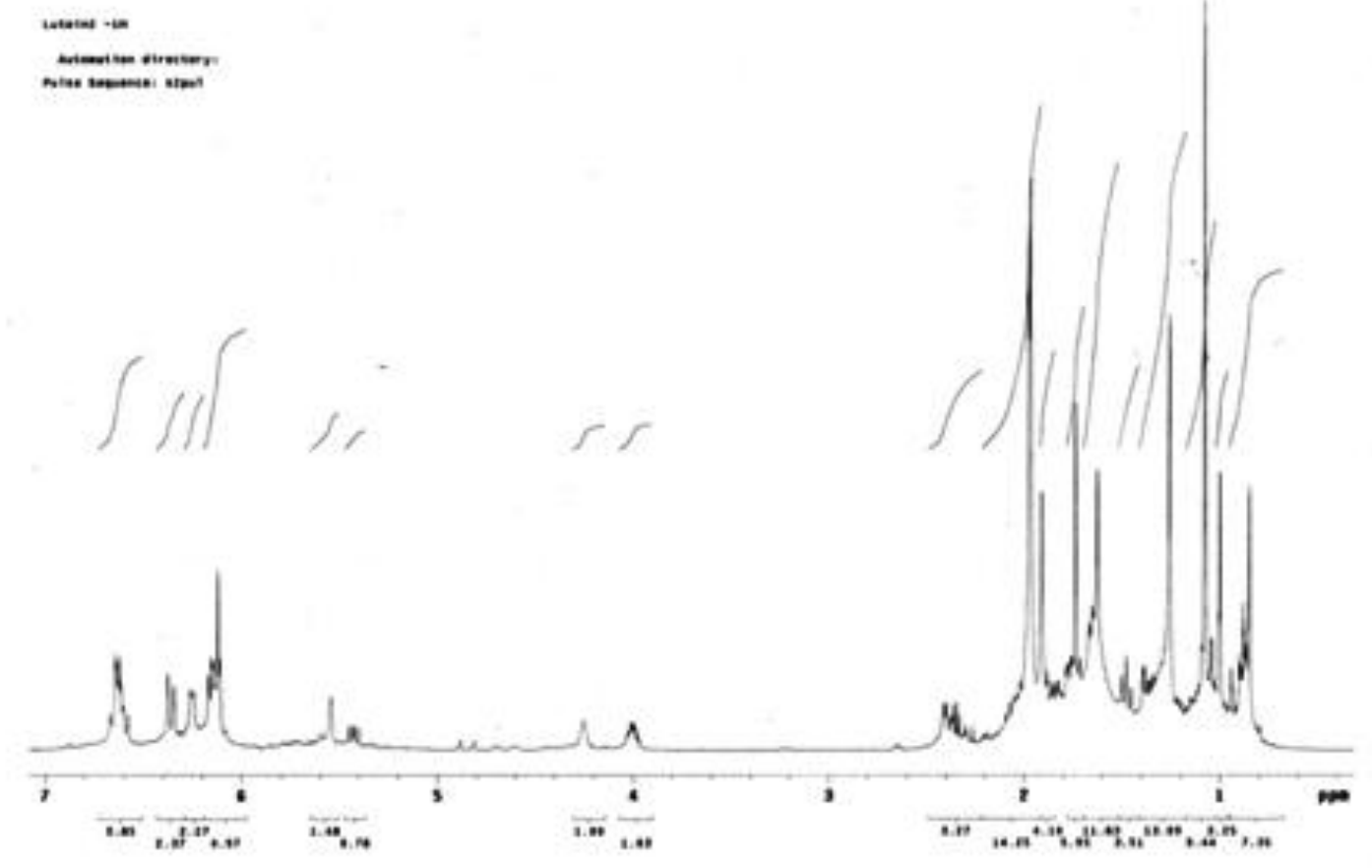

Fig. 5. H-NMR chromatograms of lutein sample after chromatographic purification. 
To confirm structure of free lutein after chromatographic purification, the purified free lutein sample was analyzed by H-NMR. The H-NMR result in Fig. 5 showed the similar peak pattern to those of Aman's work [14] and Khachik's work [15]. From the result, it can be concluded that the purified free lutein sample contained only free lutein, free lutein's stereoisomers and anhydrolutein. The H-NMR result thus verifies the HPLC analysis and the calculation of free lutein purify based on the HPLC peak area reported in Table 2.

\subsection{Adsorption of Lutein on Silica Gel}

To determine the time required for lutein to reach equilibrium adsorption on silica gel, a preliminary batch adsorption study was conducted at initial free lutein concentration of $12.0 \mu \mathrm{g} / \mathrm{ml}$ and $1 \mathrm{~g}$ of silica at $30{ }^{\circ} \mathrm{C}$. The result showed that adsorption has quickly reached equilibrium within about $5 \mathrm{~min}$. However, to ample time for all samples to attain equilibrium, $30 \mathrm{~min}$ of agitation was allowed during the subsequent adsorption experiment.

\subsubsection{Profile of equilibrium isotherm}

Adsorption isotherm of free lutein on silica gel is shown in Fig. 5. Two isotherm equations: Freundlich and Langmuir equations have been tested in the present study to establish appropriate correlation for the equilibrium curves of the adsorption data. The data fitted to the linearized models are shown in Figs. 6-7.

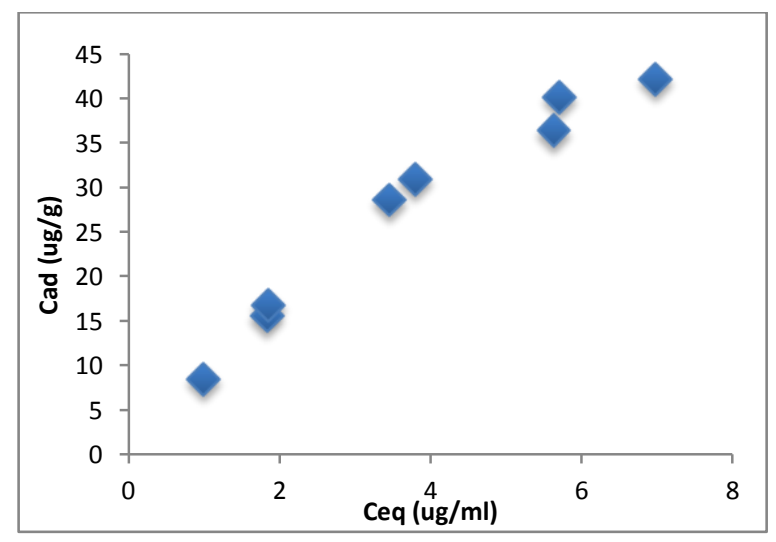

Fig. 6. Adsorption isotherm of free lutein on silica at $30^{\circ} \mathrm{C}$.

Comparing the two models, it would appear that the Langmuir isotherm can better predict the equilibrium adsorption results for free lutein on silica gel as indicated by higher $\mathrm{R}^{2}\left(\mathrm{R}^{2}=0.992\right)$.

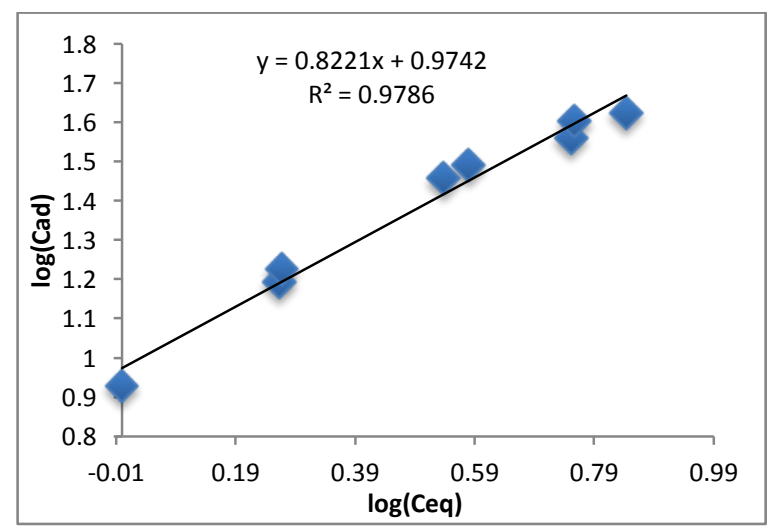

Fig. 7. Fit of Freundlich model to experimental data. 


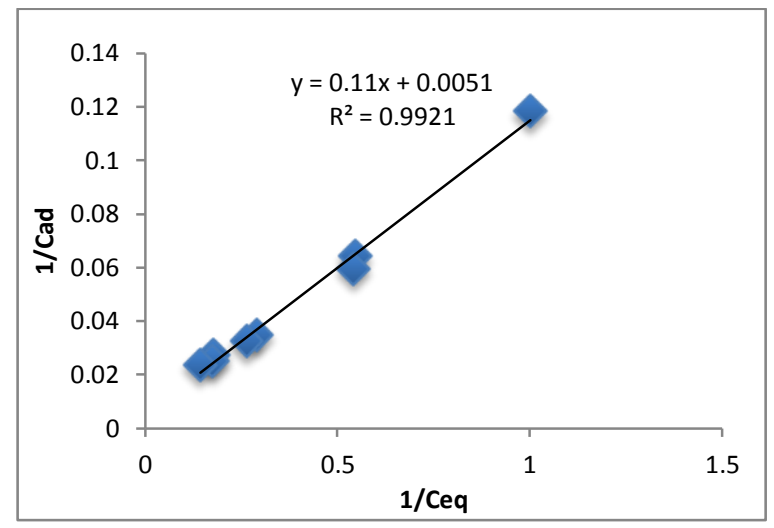

Fig. 8. Fit of Langmuir model to experimental data.

\section{Conclusions}

Screening for suitability of mobile phase composition of different ratios of hexane:ethyl acetate mixture using thin layer chromatography, Hexane: ethyl acetate mixture at 70:30 volume ratio was found to be an appropriate mobile phase on the normal phase chromatography system. Semi-preparative column chromatography by using 70:30 volume ratio of hexane:ethyl acetate as mobile phase showed the feasibility for purifying free lutein from saponified solution. The scale up factor was then used to estimate the operational conditions for preparative column chromatography such as mass of packing material, mobile phase flow rate and sample loading volume. At the most suitable condition, preparative chromatography could produce high purity free lutein $(>95 \%)$. Langmuir adsorption model was found to reasonably describe the equilibrium adsorption data of free lutein on silica gel. Nevertheless, experiments at extended range of concentrations would be needed to more accurately determine the maximum adsorption capacity.

\section{Acknowledgements}

The authors greatly appreciate Thailand Research Fund (TRF) through the Royal Golden Jubilee Ph.D. Program (RGJ-TRF) and Higher Education Research Promotion and National Research University Project of Thailand, Office of the Higher Education Commission (FW644A) for financial support.

\section{References}

[1] M. Wang, R. Tsao, S. Zhang, Z. Dong, R. Yang, J. Gong, and Y. Pei, "Antioxidant activity, mutagenicity/anti-mutagenicity, and clastogenicity/anti clastogenicity of lutein from marigold flowers," Food and Chemical Toxicology, vol. 44, pp. 1522-1529, 2006.

[2] W. Palumpitag, P. Prasitchoke, M. Goto, and A. Shotipruk, "Supercritical carbon dioxide extraction of marigold lutein fatty acid esters: Effects of cosolvents and saponification conditions," Separation Science and Technology, vol. 46, no. 4, , pp. 605-610, Jan. 2011.

[3] F. Khachik, G. Englert, R. Gary, J. Beecher, and C. Smith, "Isolation, structural elucidation, and partial synthesis of lutein dehydration products in extracts from human plasma," Journal of Chromatography B, vol. 670, pp. 219-233, 1995.

[4] F. Khachik and M. Beltsville, "Process for extraction, purification of lutein, zeaxanthin and rare carotenoids from marigold flowers and plants," United States Patent no. 6262284, 2001.

[5] B. Olmedilla, F. Granado, I. Blanco, and M. Vaquero, "Lutein, but notalpha-tocopherol, supplementation improves visual function in patients with age-related cataracts: A 2-year double blind, placebo-controlled pilot study," Nutrition, vol. 19, pp. 21-24, 2003.

[6] J. Vechpanich and A. Shotipruk, "Recovery of free lutein from tagetes erecta: Determination of suitable saponification and crystallization conditions," Separation Science and Technology, vol. 46, pp. 265$271,2011$.

[7] P. Alisa, R. Helen, and J. J. Elizabeth, "Xanthophyll (lutein, zeaxanthin) content in fruits, vegetables and corn and egg products," Journal of Food Composition and Analysis, vol. 22, pp. 9-15, 2009. 
[8] G. Dias, G. F. C. Filomena, and O. Luisa, "Carotenoids in traditional Portuguese fruits and vegetables," Food Chemistry, vol. 113, pp. 808-815, 2009.

[9] S. Shibata, C. Ishihara, and C. Matsumoto, "Improved separation method for highly purified lutein from chlorella powder using jet mill and flash column chromatography on silica gel," Journal of Agricultural and Food Chemistry, vol. 52, pp. 6283-6286, 2004.

[10] R. Piccaglia, M. Marotti, and S. Grandi, "Lutein and lutein ester content in different types of Tagetes patula and T. Erecta," Industrial Crops and Products, vol. 8, pp. 45-51, 1998.

[11] N. Kiyotaka, K. Takehiro, H. Keijiro, A. Akira, K. Fumiko, S. Phumon, T. Tsuyoshi, A. Hiroyuki, and M. Teruo, "Development of a high-performance liquid chromatography-based assay for carotenoids in human red blood cells: Application to clinical studies," Analytical Biochemistry, vol. 381, pp. 129-134, 2008.

[12] N. E. Craft and J. E. Soares, "Relative solubility, stability and absorptivity of lutein and $\beta$-carotene in organic solvents," Journal of Agricultural and Food Chemistry, vol. 40, pp. 431-434, 1992.

[13] P. Molnar, Z. Szabo, E. Osz, P. Olah, G. Toth, and J. Deli, "Separation and identification of lutein derivatives in processed foods," Chromatographia, vol. 60, pp. S101-S105, 2004.

[14] R. Aman, J. Biehl, R. Carle, J. Conrad, U. Beifuss, and A. Schieber, "Application of HPLC coupled with DAD, APcI-MS and NMR to the analysis of lutein and zeaxanthin stereoisomers in thermally processed vegetables," Food Chemistry, vol. 92, pp. 753-763, 2005.

[15] F. Khachik, G. Englert, G. R. Beecher, and J. C. Smith Jr., "Isolation, structural elucidation, and partial synthesis of lutein dehydration products in extracts from human plasma," Journal of Chromatography B, vol. 670, pp. 219-233, 1995. 
